\title{
PENGARUH KREATIVITAS GURU TERHADAP MOTIVASI BELAJAR PADA SMK VIA MEDIKA
}

\author{
Imbron,Alvin Praditya,Laura Komala \\ Dosen Fakultas Ekonomi Universitas Pamulang \\ Email : dosen02455@unpam.ac.id, dosen02164@unpam.ac.id,dosen01013@unpam.ac.id
}

\begin{abstract}
ABSTRAK
Penelitian ini bertujuan untuk mengetahui adakah pengaruh kreativitas guru terhadap motivasi siswa pada SMK Via Medika Ciputat.

Metode penelitian ini mengunakan pendekatan assosiatif metode deskriptif kuantitatif. Penelitian ini juga mengunakan teknik sampling dimana teknik sampling yaitu teknik sampling jenuh dengan sampel sebanyak 75 responden. Analisis data dengan menggunakan analisis regresi, analisis koefisien,korelasi, analisis koefisien determinasi dan uji hipotesis.

Hasil penelitian kreativitas guru pada SMK Via Medika Ciputat adanya pengaruh positif dan signifikan antara kreativitas guru terhadap motivasi siswa yang diperoleh dari persamaan regresi $\mathrm{Y}=15,063+0.615 \mathrm{X}$. Nilai konstanta sebanyak 15,063 dan koefisien regresi 0,615 ,koefisien regresi bernilai angka yang menunjukan positif.Nilai koefisien korelasi sebanyak 0,918 atau memiliki pengaruh yang sangat kuat dan hasil nilai koefisien determinasi sebanyak $58.2 \%$ dan sisanya sebanyak $41.8 \%$ dipengaruhi dengan beberapa faktor lain.Uji hipotesis diperoleh $t$ hitung $>\mathrm{t}_{\text {tabel }}$ yaitu 10.09>1.66 yang artinya bahwa $\mathrm{H}_{0}$ ditolak dan $\mathrm{H}_{\mathrm{a}}$ diterima, artinya Kreativitas Guru (X) memiliki pengaruh yang cukup signifikan kepada terhadap Motivasi Siswa (Y).
\end{abstract}

\section{Kata kunci : Kreativitas Guru, Motivasi Belajar}

\section{ABSTRACT}

This study aims to determine whether there is an effect of teacher creativity on student motivation at SMK Via Medika Ciputat.

This research method uses associative approach quantitative descriptive method. This study also uses a sampling technique where the sampling technique is saturated sampling technique with a sample of 75 respondents. Data analysis using regression analysis, coefficient analysis, correlation, determination coefficient analysis and hypothesis testing.

The results of the research on teacher creativity at Vocational High School Via Medika Ciputat, there is a positive and significant influence between teacher creativity on student motivation obtained from the regression equation $\mathrm{Y}=15.063+0.615 \mathrm{X}$. The constant value is 15.063 and the regression coefficient is 0.615 , the regression coefficient has a numerical value that shows positive value. The correlation coefficient is 0.918 or has a very strong influence and the results of the coefficient of determination are $58.2 \%$ and the remaining $41.8 \%$ is influenced by several other factors. meaning that Teacher Creativity (X) has a significant influence on Student Motivation (Y).

Keywords: Teacher Creativity, Learning Motivation

\section{PENDAHULUAN}

A. Latar Belakang.

Dalam kehidupan manusia selain memenuhi kebutuhan premiernya juga harus memenuhi kebutuhan sekundernya salah satunya adalah pendidikan, karena pendidikan adalah salah satu usaha Untuk mendewasakan manusia dengan upaya pengajaran dan pelatihan. 
Kita tahu bahwa Indonesia memiliki Sumber Daya Manusia (SDM) yang sangat banyak,ini merupakan aset yang harus di optimalkan untuk kemajuan bangsa yaitu dengan cara memberikan pendidikan yang baik, didukung oleh sarana fasilitas yang baik juga. Agar proses pendidikan dapat berjalan dengan optimal dan tepat sasaran.

Pendidikan yang terarah adalah bagian dari solusi dalam hasil belajar siswa karena program pendidikan yang ada menuntut untuk menyediakan sumber daya manusia yang ,kreatif dan dapat di handalkan. Maka dari itu, untuk terciptanya sumber daya manusia yang handal maka di perlukan proses kegiatan belajar mengajar yang terencana dan efektif.

"Menurut SC. Utami Munandar (1977)," Kreativitas ialah kemampuan untuk membuat kombinasi baru, berdasarkan data, informasi atau unsurunsur yang ada. Kreativitas juga dapat diartikan sebagai kemampuan menemukan banyak adanya jawaban dari terhadap suatu masalah, di dalam hal ini penekanannya adalah kuantitas, ketepatgunaan, dan keragaman jawaban. Pengertian lainnya ialah kemampuan yang mencerminkan kelancaran, keluwesan dan orisinalitas dalam berfikir serta mengolaborasi (mengembangkan, memperkaya memperinci suatu gagasan)."

Seseorang bisa dikatakan berhasil jika hasil belajar yang diperolehnya dapat memuaskan dan kebutuhan belajar yang diinginkan dapat terpenuhi.Maksud memuaskan disini adalah siswa dapat menerapkan atau mempraktekkan ilmu yang diajarkan oleh seorang guru dalam proses pembelajaran tersebut. Sedangkan untuk memenuhi kebutuhan belajar anak didik dapat dipengaruhi beberapa faktor,yaitu adanya faktor luar maupun faktor dalam pribadi anak didik itu sendiri. Salah satu faktor luar yang harus di perhatikan yakni tenaga pengajar yaitu seorang guru.Sementara faktor dalam yaitu kondisi jasmani dan rohani siswa.sebab karena itu seorang guru harus dapat membuka proses pembelajaran dengan pendahuluan semenarik mungkin, dan dapat mengimprovisasi dalam menjelaskan materi seperti bercerita dengan sedikit ada unsur humor sehingga siswa tidak cepat merasa bosan dan semangat dalam proses pembelajaran tersebut. Untuk mendukung proses pembelajaran ini, di perlukan guru yang berkompeten di bidangnya yang dapat memberikan materi pengajaran serta mampu memotivasi peserta didik yang dapat menimbulkan minat dan bakatnya.

Ada dua hal yang mempengaruhi yaitu Motivasi dan belajar.Belajar ialah perubahan tingkah laku secara relatif permanen dan juga secara potensial terjadi sebagai hasil dari praktik atau penguatan.

Ada beberapa definisi motivasi, seperti yang diungkapkan. "Menurut Hamzah B.Uno (2006) motivasi adalah dorongan yang ada dalam diri individu yang dapat menggerakkan seseorang itu untuk melakukan sesuatu." “ Menurut Mc. Donald, dikutip dalam Oemar Hamalik (2001) Motivasi Belajar adalah perubahan energi dalam diri (pribadi) seseorang yang ditandai dengan timbulnya perasaan dan reaksi untuk mencapai tujuan. Sedangkan menurut Dalyono, (2005) Motivasi Belajar adalah daya penggerak/pendorong untuk melakukan suatu pekerjaan (belajar)."

Maka dari itu peran seorang guru dalam memotivasi siswa adalah hal yang amat penting dalam proses belajar mengajar. Dengan kemajuan riset di bidang kreativitas,banyak ilmu -ilmu yang mempelajari tetang kreativitas dan berbagai model pembelajaran kratif,hal ini bisa menjadi faktor utama untuk mengembangkan kreativitas dan krativitas dapat di ajarkan oleh seorang guru maka di butuhkanlah guru yang memiliki kemampuan kreatiivitas yang tinggi

Di kehidupan nyata sering ditemukan siswa yang mempunyai kemampuan cukup tinggi 
tetapi gagal dalam belajarnya.Ini disebabkan oleh minimnya motivasi dalam diri anak didik tersebut. Motivasi juga timbul karena adanya daya tarik dari luar dan juga datang dari dalam hati sanubari. "Menurut Mc. Donald "Motivasi adalah perubahan energi dalam diri seseorang yang ditandai dengan munculnya "feeling" dan didahului dengan tanggapan terhadap adanya tujuan" (Sardiman, 2011: 73).”

Motivasi amatlah penting karan untuk mencapai sebuat pembelajaran hal ini juga memnajdi salah satu factor yang mampu meningkatkan kualitas pembelajaran. Dengan motivasi yang tinggi maka siswa dapat belajar dengan sunguh sunguh. Penelitian ini di lakukan dengan mengambil siswa kelass $X$ s/d XII SMK VIA Medika,hal ini di karenakan dari hasil pengamatan sementara dapat di lihat banyak siswa/siswi kurang semangat,banyak mengeluh dalam proses pembelajaran.

\section{B. Identifikasi Masalah}

1. Kreativitas guru SMK Via medika belum optimal

2. Kreativitas guru SMK Via medika belum optimal

3. Guru yang ada belum bekerja sesuai SOP yang ada pada SMK Via Medika

4. Tingkat motivasi siswa dalam belajar pada SMK VIA Media belum maksimal

5. Kreativitas guru dalam kegiatan belajar mengajar untuk mendorong

minat,motivasi,belajar,siswa,yang ,belajar.siswa yang masi belum efektif.

\section{Rumusan Masalah}

1. Bagaimana kreativitas guru pada SMK Via Medika?

2. Bagaimana Motivasi Belajar Siswa Pada SMK Via Medika?

3. Dan Seberapa besar pengaruh kreativitas guru terhadap motivasi belajar siswa SMK Via Medika?

\section{TINJAUAN PUSTAKA}

\section{A. Kreativitas}

\section{Pengertian Kreativitas}

Kreativitas adalah sebuah keampuan untuk memecahkan permasalahan yang memungkinkan oarang trsebut memecahakan ide yang menghasilakn fungsi kegunaan yang secarah penuh berkembang.

“ Menurut Slameto (2010:145) dalam buku "Belajar dan Faktor-faktor yang mempengaruhinya bahwa: Kreativitas berhubungan dengan penemuan sesuatu, mengenai hal yang menghasilkan sesuatu yang baru dengan menggunakan sesuatu yang telah ada."

\section{B. Motivasi}

\section{Pengertian Motivasi}

Dalam proses belajar kita memerlukan semangat agar apa yang di pelajari dapat masuk ke dalam diri kita hal itu sering disebut dengan nama Motivasi. Motivasi merupakan dorongan seseorang untuk melakukan hal yang di inginkan olehnya untuk mencapai tujuanya , motivasi sangatlah berperan dan sanagt mempengaruhi pembelajaran.

“ Menurut Hamzah B.Uno (2006) motivasi adalah dorongan yang ada dalam diri individu yang dapat menggerakkan seseorang itu untuk melakukan sesuatu."

"Menurut Mc. Donald, dikutip dalam Oemar Hamalik (2001) Motivasi Belajar adalah perubahan energi dalam diri (pribadi) seseorang yang ditandai dengan timbulnya perasaan dan reaksi untuk mencapai tujuan."

"Sedangkan menurut Dalyono, (2005)

Motivasi Belajar adalah daya penggerak/pendorong untuk melakukan suatu pekerjaan (belajar).”

\section{Hipotesis}


1) $\mathrm{H}_{1}$ : Tidak terdapat pengaruh kreativitas guru $\left(\mathrm{X}_{1}\right)$ terhadap motivasi belajar ( $\mathrm{Y}$ )

2) $\mathrm{Ha}_{1}:$ Terdapat Pengaruh Kreativitas guru $\left(\mathrm{X}_{1}\right)$ terhadap motivasi belajar ( $\mathrm{Y}$ )

\section{METODOLOGI PENELITAN}

\section{A. Ruang Lingkup Penelitaan}

1. Tempat Penelitian

Penelitian dilakukan pada SMK Via Medika yang berada di Jl. Wr supratman no 1 cempaka putih,ciputat timur, tangerang selatan

\section{Waktu Peneltian}

Penelitian ini dikerjakan dalam waktu 3 bulan di mulai dari bulan januari hingga bulan juni 2020.Penelitian ini dengan cara bertahap dimulai dengan persiapan penelitian berupa menulis proposal judul penelitian, seminar proposal judul skripsi, pengajuan surat izin, pembuatan kuesioer, konsultasi,penyebaran kuesioner,pengolahan data,sertapenyusunan penelitian.

\section{B. Populasi dan Sampel}

\section{Populasi}

Populasi penelitian ini merupakan seluruh siswa kelas $\mathrm{X}$, XI DAN XII SMK Via medika yang berjumlah 75 siswa

2. Sampel

Sampel yang dijadikan objek dalam peneitian adalah seluruh siswa kelas X, XI DAN XII SMK Via medika yang berjumlah 75 siswa

\section{Metode Analisis Data Penelitian dan Pembahasan}

,Hasil

\begin{abstract}
Data data variable kreativitas guru diukur dengan menggunakan angket yang terdiri dari 20 pertanyaan dengan skala 15.Penelitimen coba mengdiskripisikan variabel kreativitas guru. Distribusi kreativitas guru disajikan sebagai berikut:
\end{abstract}

Tabel 1

Deskripsi presentase Kreativitas Guru (X)

\begin{tabular}{|l|l|l|}
\hline NO & $\begin{array}{l}\text { Presentas } \\
\text { e }\end{array}$ & Kategori \\
\hline 1 & $18,53 \%$ & Sangat Setuju \\
\hline 2 & $52,27 \%$ & Setuju \\
\hline 3 & $25,20 \%$ & Ragu-Ragu \\
\hline 4 & $3,33 \%$ & Tidak Setuju \\
\hline 5 & $0,67 \%$ & $\begin{array}{l}\text { Sangat } \\
\text { Setuju }\end{array}$ \\
\hline $\begin{array}{l}\text { Jumla } \\
\text { h }\end{array}$ & $100,00 \%$ & \\
\hline
\end{tabular}

Deskripsi data variabel kreativitas guru $(\mathrm{X})$ menunjukkan jumlah seluruh skor sebanyak 2885 dan angka rata-rata skor 3,85 dan masuk kedalam rentang kategori Baik, serta skor jawaban Sangat Setuju (SS) sebanyak 18,53\%, Setuju (S) sebanyak $52,27 \%$, Ragu-Ragu (RR) sebanyak $25,20 \%$, Tidak Setuju (TS) sebanyak 3,33\% dan Sangat Tidak Setuju (STS) sebanyak $0,67 \%$.

Variabel Kreativitas (X) ini mendapatkan skor rata-rata terendah yang harus ditingkatkan adalah yaitu sebanyak 3,76\%. Pada instrumen ini guru harus lebih bersemangat dalam menjelaskan pelajaran. Agar mempermudah dalam pembacaan data tentang kretivitas guru, adapun diagramnya sebagai berikut:

\section{Deskripsi Hasil Penelitian}

\section{a. Kreativitas Guru}




\section{Gambar 1}

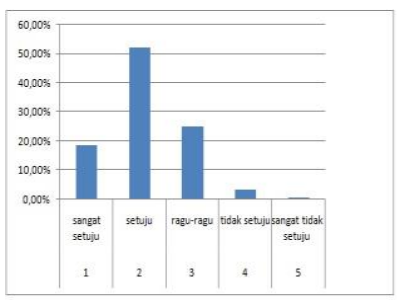

Agar mempermudah dalam penjabaran data tentang kretivitas guru, adapun diagramnya sebagai berikut:

Gambar 2

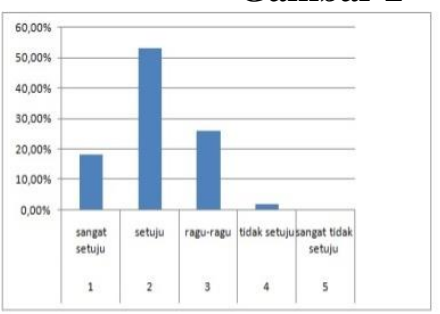

siswa dalam pembelajaran.

\section{b. Pembahasan}

Tabel 2

Deskripsi presentase

Motivasi Belajar Siswa(Y)

\begin{tabular}{|l|l|l|}
\hline NO & Presentase & Kategori \\
\hline 1 & $18,40 \%$ & $\begin{array}{l}\text { sangat } \\
\text { setuju }\end{array}$ \\
\hline 2 & $53,07 \%$ & Setuju \\
\hline 3 & $26,13 \%$ & ragu-ragu \\
\hline 4 & $2,13 \%$ & tidak setuju \\
\hline 5 & $0,27 \%$ & $\begin{array}{l}\text { sangat tidak } \\
\text { setuju }\end{array}$ \\
\hline Jumlah & $100,00 \%$ & \\
\hline
\end{tabular}

Dari data di atas dapat disimpulkan bahwa instrumen variabel Motivasi belajar siswa (Y) menjukkan total skor sebanyak 2094 dan rata-rata skor 4,12 dan masuk kedalam rentang kategori Baik, serta skor jawaban Sangat Setuju (SS) sebanyak $18,40 \%$, Setuju (S) sebanyak 53,07\%, Ragu-Ragu (RR) sebanyak 26,13\%, Tidak Setuju (TS) sebanyak 2,13\% dan Sangat Tidak Setuju (STS) sebanyak 0,27\%.

\section{Kreativitas Guru terhadap Motivasi Siswa SMK Via Medika}

\section{1) Analisa Kuantitatif}

Untuk mengetahui
seberapa besar Pengaruh Kreativitas Guru terhadap motivasi belajar siswa pada SMK Via Medika penulis menggunakan analisa :

\section{a) Persamaan Regresi Linear Sederhana}

Analisis koefisien regresi dilakukan untuk mengetahui adanya pengaruh antaraa variabel Kreativitas Guru (X) terhadap variabel yaitu Motivasi (Y) Siswa. Tujuanya Untuk mengetahui adanya pengaruh antara kedua variabel tersebut, maka dapat digunakan penyelesaiannya sebagai berikut :

Dari pengumpulan kuesioner sebanyak 75 responden dengan kuesioner Kreativitas Guru (X) dan Motivasi Siswa (Y) masing-masing 

Pamulang

sebanyak 10 pernyataan dan dihasilkan data sebagai berikut :

\begin{tabular}{|l|c|c|c|c|c|}
\hline $\begin{array}{l}\text { TOTA } \\
\text { L }\end{array}$ & & & & & \\
\cline { 1 - 3 } JUML & 28 & 29 & 1130 & 1138 & 1130 \\
AH & 85 & 04 & 99 & 26 & 14 \\
\hline
\end{tabular}

guru berpengaruh positif kepada terhadap motivasi siswa SMK Via Medika artinya jika kreativitas yang dimiliki oleh guru sesuai standar sekolah maka bisa menaikan motivasi siswa, begitu pula sebaliknya. Koefisien regresi $X=$ 0.615 , maka skor variabel $\mathrm{Y}$ akan bertambah 1 satuan dengan asumsi konstanta 15.063 satuan.

\section{b) Korelasi Product Moment}

Peneliti ini untuk lebih memahami hubungan antara variabel $x$ (kreativitas guru) dengan variabel y (motivasi siswa),peneliti menggunakan rumus korelasi product moment sebagai berikut ini Diketahui:

$$
\begin{aligned}
N & =75 \\
\sum X & =2885 \\
\sum Y & =2904 \\
\sum X^{2} & =8425885 \\
\sum Y^{2} & =113826 \\
\sum X Y & =210113
\end{aligned}
$$$$
a=\frac{2904-1774,28}{75}
$$

$$
\begin{array}{ll}
a & =\frac{1129,725}{75} \\
a & =15,063
\end{array}
$$

Dengan demikian dapat dihasilkan angka persamaan berdasarkan dari output coefficients $\mathrm{Y}=15,063+0.615 \mathrm{X}$ artinya bahwa peruubahan $Y$ sejalur dengan perubahan $X$. Jadi nilai $Y$ bisa meningkat jika $X$ meningkat, sebaliknya nilai $\mathrm{Y}$ bisa menurun jika $X$ menurun. Peneliti menyimpulkan bahwa kreativitas
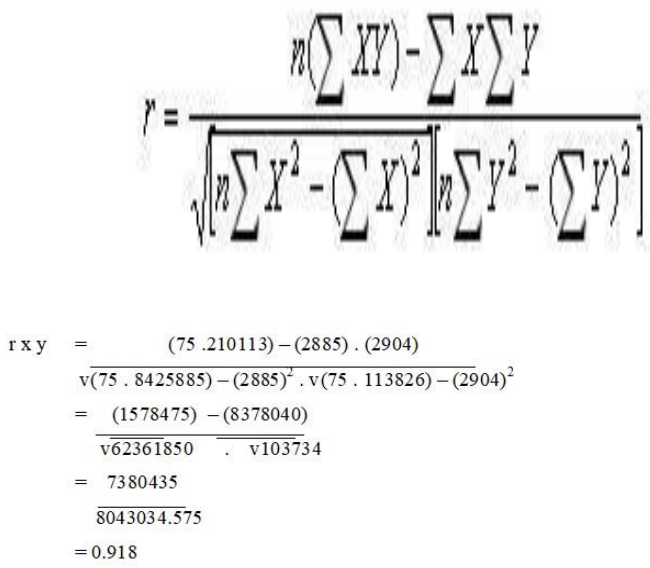
Peneliti menggunakan rumus koefisien korelasi product moment dan memperoleh yaitu 0.918 yang berarti tingkat pengaruh antara kreativitas guru terhadap motivasi siswa yaitu berada di tingkat yang begitu sangat kuat.

c) Koefisien Determinasi

Berikut untuk mengetahui seberapa besar adanya Pengaruh Kreativitas Guru terhadap Motivasi Siswa digunakan rumus koefisien determinasi sebagai berikut :

KD (koefisien determinasi)

$=\mathrm{r}^{2} \times 100 \%$

$=(0.763)^{2} \times 100 \%$

$=58.2$

bahwa $\begin{aligned} & \text { Hal ini membuktikan } \\ & \text { besarnya Pengaruh }\end{aligned}$

Kreativitas Guru terhadap Motivasi

Siswa sebesar $58.2 \%$ dan sisanya sebesar $\quad 41.8 \%$ dipengaruhi beberapa faktor lain.

\section{d) Uji Signifikasi}

Berdasarkan hasil perhitungan di atas, maka peneliti melakukan pengujian hipotesa dengan cara membandingkan nilai $t_{\text {tabel }}$ dengan $t_{\text {hitung. }}$ Nilai $t_{\text {tabel }}$ ditentukan berdasarkan tingkat signifikan $(\alpha)$ yang digunakan dan derajat kebebasan $(\mathrm{df}=\mathrm{n}-2)$ yang meningkatnya tergantung dari jumlah sampel (n). Taraf nyata yang penulis memakai angka sebesar 0.05 (5\%). berikut :

Rumus $\mathrm{t}$ hitung adalah sebagai

$$
t_{\text {hitung }}=\frac{r \sqrt{\mathrm{n}-2}}{\sqrt{1-\mathrm{r}^{2}}}
$$

Dimana : $r=$ koefisien korelasi $\mathrm{n}=$ banyaknya responden

$\mathrm{t}=\frac{0.763 \sqrt{75-2}}{\sqrt{1-(0.763)^{2}}}$

$$
\begin{aligned}
\mathrm{t} & =\frac{0.763 \sqrt{73}}{\sqrt{1-0.763}} \\
\mathrm{t} & =\frac{6.519}{0.646} \\
\mathrm{t} & =10.09
\end{aligned}
$$

Pengambilan keputusan menggunakan angka pembanding $t_{\text {tabel }}$ dengan kriteria sebagai berikut:

Jika $\mathrm{t}$ hitung $>\mathrm{t}$ tabel $\mathrm{H}_{0}$ ditolak $; \mathrm{H}_{\mathrm{a}}$ diterima (signifikan)

Jika $\mathrm{t}$ hitung $\leq \mathrm{t}$ tabel $\mathrm{H}_{0}$ diterima ; $\mathrm{H}_{\mathrm{a}}$ ditolak (tidak signifikan)

Dari berdasarkan hasil pengujian rumus di atas maka $t_{\text {hit }}>\mathrm{t}_{\text {tab }}$ yaitu 10.09>1.66 yang artinya bahwa $\mathrm{H}_{0}$ ditolak dan $\mathrm{H}_{\mathrm{a}}$ diterima, artinya Kreativitas Guru (X) mempunyai pengaruh yang signifikan terhadap Motivasi Siswa (Y).

Dan dari hasil pengolahan data dihasilkan nilai koefisien korelasi sebesar $r=0.763$ yang berarti korelasi antara kreativitas guru dengan motivasi siswa berada pada kategori sangat kuat dan signifikan. Sedangkan nilai koefisien determinasi yang diperoleh sebesar 58.2\% menunjukan bahwa motivasi siswa dipengaruhi oleh kreativitas guru sebesar $58.2 \%$ sisanya sebesar $41.8 \%$ dipengaruhi oleh faktor lain.

\section{PENUTUP}

\section{A. Kesimpulan}

1. Peneliti menjelaskan dan dapat disimpulkan bahwa, instrumen variabel kreativitas guru (X) menunjukkan total skor sebesar 2885 dan rata-rata skor 3,85 dan masuk kedalam rentang kategori Baik, serta skor jawaban Sangat Setuju (SS) sebesar 18,53\%, Setuju (S) sebesar 52,27\%, Ragu-Ragu (RR) sebesar $25,20 \%$, Tidak Setuju (TS) sebesar 3,33\% dan Sangat Tidak Setuju (STS) sebesar 0,67\%.. 
2. Berdasarkan penjelasan di atas dapat disimpulkan bahwa, instrumen variabel Motivasi belajar siswa (Y) menjukkan total skor sebesar 2094 dan rata-rata skor 4,12 dan masuk kedalam rentang kategori Baik, serta skor jawaban Sangat Setuju (SS) sebesar 18,40\%, Setuju (S) sebesar 53,07\%, RaguRagu (RR) sebesar $26,13 \%$, Tidak Setuju (TS) sebesar 2,13\% dan Sangat Tidak Setuju (STS) sebesar $0,27 \%$.

3. Kreativitas Guru (X) mempunyai pengaruh terhadap Motivasi Belajar Siswa (Y) Pada SMK VIA Medika Ciputat.berdasarkan dari output coefficients $\mathrm{Y}=15,063+0.615 \mathrm{X}$ artinya bahwa perubahan $\mathrm{Y}$ searah dengan perubahan $X$. Jadi nilai $Y$ akan naik jika nilai pun $X$ ikut naik, sebaliknya nilai $\mathrm{Y}$ akan rendah jika nilai $X$ merendah.

Jadi dapat disimpulkan bahwa kreativitas guru berpengaruh positif terhadap motivasi siswa SMK VIA Medika. artinya jika kreativitas yang dimiliki oleh guru sesuai standar sekolah maka akan meningkatkan motivasi siswa, begitu pula sebaliknya. Koefisien regresi $X=0.615$, maka skor variabel $\mathrm{Y}$ akan bertambah 1 satuan dengan asumsi konstanta 15.063 satuan. Dan Berdasarkan hasil Uji Koefisien Korelasi, dapat disimpulkan terdapat pengaruh antara Kreativitas Guru terhadap Motivasi Siswa pada SMK VIA Medika Ciputat yaitu sebesar 0,918. Jika dilihat dari tabel interpretasi koefisien korelasi masuk pada interval $0,80-1,000$ dengan tingkat pengaruh dinyatakan sangat kuat. Hal ini menandakan bahwa terdapat hubungan yang sangat kuat antara variabel X (Kreativitas) dengan variabel Y (Motivasi) Pada SMK VIA Medika Ciputat.

\section{B. Saran}

Berdasarkan kesimpulan diatas, maka penulis mengajukan beberapa saran yang diharapkan dapat bermanfaat bagi SMK VIA Medika adapun saran tersebut adalah sebagai berikut:

1. Dari Pengaruh Kreativitas Guru pada SMK VIA Medika Ciputat sudah baik, namun harus di perhatikan lagi dari sisi guru nya sendiri, di karenakan Variabel Kreativitas $\left(\mathrm{X}_{1}\right)$ yang harus ditingkatkan adalah pada instrumen no 3 yang mendapatkan skor rata-rata terendah sebesar 3,76. Pada instrumen ini guru harus lebih bersemangat dalam menjelaskan pelajaran.

2. Dilihat dari segi Motivasi Siswa pada SMK VIA Medika Ciputat harus lebih ditingkatkan lagi pada Variabel Motivasi belajar siswa (X) yang harus ditingkatkan adalah pada instrumen no 7 yang mendapatkan skor rata-rata terendah sebesar 3,73. Pada instrumen ini agar guru harus selalu membuat kelompok diskusi untuk mencari solusi dalam suatu masalah

3. Untuk peneliti selanjutnya disarankan mengunakan varibelvaribel lainya agar hasil penelitian 
lebih maksimal dan hasil yang maksimal bisa untuk memperbaiki kondisi permasalahan sekolah agar sekolah lebih baik lagi.

\section{DAFTAR PUSTAKA}

A. M, Sadirman. 2007. Interaksi Dan Motivasi Belajar Mengajar. Jakarta : PT Raja Grafindo Persada.

Sardiman. 2011. Interaksi dan Motivasi Belajar Mengajar. Jakarta: Rajawali Press.

, Sardiman. 2012. Interaksi dan Motivasi Belajar Mengajar, Jakarta: Rajawali Pers.

Abraham H. Maslow. 1994. Motivasi dan Kepribadian (Teori Motivasi dengan Pendekatan hierarki Kebutuhan Manusia). Jakarta: PT PBP.

Al-Khalili, Amal Abdus Salam. 2006. Pengembangan Kreativitas Anak, Jakarta: Pustaka Al-Kautsar.

B.Uno, Hamzah. 2006. Teori Motivasi dan Pengukuranmya Analisis Di Bidang Pendidikan. Jakarta : Bumi Aksara.

Carin, A. A. Sund R.B. 1975. Teaching Science Through Discovery. Thir Editional Charles Merril Publishing Company. Colombus, Ohio.

Chaplin, J.P. 1989. Kamus Lengkap Psikologi. Terj. Dr. Kartono dan Kartini. Jakarta: PT. Raja Grafindo Persada.

Dalyono. 2005. Interaksi dan Motivasi Belajar Mengajar. Jakarta : Raja Grafindo.

E. Mulyasa. 2005. Menjadi Guru Profesional. Bandung: PT. Remaja Rosda Karya.
Hamali k, Oemar. 2001. Proses Mengajar, Jakarta : Bumi Aksara

Belajar

Hasbullah. 2006. Otonomi Pendidikan: Kebijakan Otonomi Daerah dan Implikasinya terhadap Penyelenggaraan Pendidikan. Jakarta: Raja Grafindo Persada.

James J. Gallagher. 1985. Teaching The Gifted Child. Boston: Allyn And Bacon, Inc.

Krisnaldy, K., Pasaribu, V. L. D., \& Batubara, A. S. (2020). Analisis Pengaruh Kedisiplinan Terhadap Performa Pegawai Kelurahan Rempoa, Kota Tangerang Selatan. Jurnal Mandiri: Ilmu Pengetahuan, Seni, Dan Teknologi, 4(2), 131-138.

Krisnaldy, K., Pasaribu, V. L. D., \& Senen, S. (2019). Pengaruh Budaya Organisasi, Lingkungan Kerja Dan Iklim Organisasi Terhadap Motivasi Pegawai Serta Dampaknya Terhadap Kepuasan Kerja. Jurnal Semarak, 2(2), 164-183.

Laggulung, Hasan. 1995. Manusia dan Pendidikan. Jakarta: Al-Husna Dzikra.

Hasan. 1991. Kreativitas dan

Pendidikan Islam, Jakarta: Pustaka AlHusna

Munandar, S.C. Utami. 1992, Mengembangkan Bakat Anak, Jakarta : Gramedia.

, Utami S.C. 1977. Creativity and Education, Disertasi Doktor U.I. Jakarta : Universitas Indonesia.

Oemar, Hamalik. 2008. Perencanaan Pengajaran Bedasarkan Pendekatan Sistem. Jakarta: PT Bumi Aksara.

Pasaribu, V. L. D., Susanti, F., \& Hartuti, E. T. K. (2019). Memotivasi Siswa dan Siswi SMK Letris Indonesia di Dalam Menentukan Pilihan Untuk Melanjutkan Pendidikan Atau Bekerja Setelah Lulus Sekolah. Jurnal Pengabdian Dharma Laksana, 1(2), 161-172. 
Pasaribu, V. L. D., \& Krisnaldy, K. (2018). ANALISIS KEPUASAN JAMA'AH PADA

KINERJA DEWAN KEMAKMURAN MASJID AL-HIDAYAH PERIODE TAHUN 2017. KREATIF: Jurnal Ilmiah Prodi Manajemen Universitas Pamulang, 6(4), 41-51.

Pasaribu, V. L. D., Krisnaldy, K., \& Warasto, H. N. (2020). Pengaruh Gaya Kepemimpinan, Disiplin Kerja Dan Kompensasi Terhadap Kinerja Pegawai (Studi kasus kelurahan Pisangan Ciputat). Jurnal Disrupsi Bisnis: Jurnal Ilmiah Prodi Manajemen, Fakultas Ekonomi, Universitas Pamulang, 3(1).

Pasaribu, V. L. D., \& Krisnaldy, K. (2020). PENGARUH GAYA KEPEMIMPINAN, DISIPLIN KERJA DAN KOMPENSASI TERHADAP HASIL KINERJA KARYAWAN KELURAHAN PISANGAN CIPUTAT. PROCEEDINGS UNIVERSITAS PAMULANG, 1(1).

Rachmawati, Yeni dan Kurniati, Euis. 2010. Strategi Pengembangan Kreativitas Pada Anak Usia Taman Kanak-Kanak. Jakarta: Kencana.

Semiawan.1997. Perspektif Pendidikan Anak Berbakat. Jakarta: Grasindo.

Slameto. 2010. Belajar dan Faktor yang mempengaruhinya. Jakarta: Rineka Cipta.

Sugiyono. 2015. Metode Penelitian Kombinasi (Mix Methods). Bandung: Alfabeta.

Supriadi, Dedi. 1994. Kreativitas, Kebudayaan dan Perkembangan IPTEK. Bangung: Alfabeta. 